\title{
ПРОБЛЕМЫ ОБУЧЕНИЯ КИТАЙСКИХ СТУДЕНТОВ В РОССИЙСКОМ ПЕДАГОГИЧЕСКОМ ВУЗЕ
}

\section{PROBLEMS OF TEACHING CHINESE STUDENTS AT THE RUSSIAN PEDAGOGICAL UNIVERSITY}

\section{E. Sokolova} Fu Li

Summary: The article analyzes the problems of teaching foreign students in Russian universities. On the basis of the questionnaire, the difficulties encountered by the students of the PRC in the process of studying at the Faculty of Fine Arts of the Russian State Pedagogical University were identified, the reasons for the emergence of difficulties were analyzed; recommendations for improving the efficiency of the educational process are offered.

Keywords: students of the PRC, art and pedagogical education, learning problems.

\author{
Соколова Елена Николаевна \\ К.искусствоведения, доцент, РГПУ им. А.И. Герцена \\ (Санкт-Петербург), \\ rgpusokolova@yandex.ru \\ Ли Фу \\ Аспирант, РГПУ им. А.И. Герцена (Санкт-Петербург) \\ afulili@yandex.com
}

Аннотация: В статье проведен анализ проблем обучения иностранных студентов в Российских вузах. На основе анкетирования выявлены трудности, с которыми сталкиваются студенты КНР в процессе обучения на факультете изобразительного искусства Российского государственного педагогического университета, проанализированы причины возникновения трудностей; предложены рекомендации для повышения эффективности учебного процесса.

Ключевые слова: студенты КНР, художественно-педагогическое образование, проблемы обучения.

\section{Актуальность}

о мере развития глобализации количество студентов, которые выбирают обучение за границей, стремятся расширить свой кругозор, знакомятся с различными культурными обычаями, изучают иностранные языки и специальности, постепенно увеличивается. Россия и Китай всегда были дружественными соседями [1]. С 2006 года количество китайских студентов в России лидирует среди всех студентов-иностранцев. Китай сохраняет эту позицию в течение многих лет [13]. Поиск эффективных способов организации обучения при постоянном увеличении количества иностранных обучаемых в российских вузах при изменении условий и средств обучения на современном этапе остается актуальным.

Целью данной статьи является выявление проблем, с которыми сталкиваются студенты КНР в современной ситуации в процессе обучения на факультете изобразительного искусства Российского государственного педагогического университета им. А.И. Герцена; определение рекомендаций, направленных на повышение эффективности учебного процесса.

\section{Степень изученности}

Вопросы обучения иностранных студентов долгие годы находятся в поле зрения исследователей.

Социокультурные особенности адаптации и про- фессиональной социализации иностранных студентов в российском вузе исследовала И. Камара. В исследовании выявлено, что во многом эти трудности обусловлены культурными различиями, одним из способов улучшения этого положения является содействие интеграции иностранных студентов в российское общество [4].

Безусловно, основная трудность, с которой сталкиваются иностранные студенты в иностранном вузе, отмечает большинство исследователей - проблема понимания преподавателя из-за языкового барьера [3]. Л. Тянь пришла к выводу, что иностранные студенты из Китая с трудом изучают русский язык и имеют низкую коммуникативную компетентность [11]. Исследователь Е.Ю. Котельникова отмечает, что языковой барьер является самой существенной проблемой, с решением которой связаны многие стороны адаптации: и образовательная, и социально-культурная, и психологическая [5].

Следующая сложность, вытекающая из предыдущей, заключается в том, что китайцы недостаточно общаются с другими студентами, которые могли бы помочь им влиться в среду и лучше преодолевать коммуникативные проблемы. Большинство китайцев отмечает, что круг русских друзей у них невелик, что иногда они чувствуют негативное отношение к себе со стороны местных жителей. Несмотря на изучение русского языка и постижение русской культуры, они не сливаются со средой, не интегрируются в российское студенчество, как описывается в исследованиях М.Н. Кухоренко и К.С. Лелюшкина [6]. 
Серьезной проблемой могут стать и отличия в менталитете. Я. Ван выделяет у китайских студентов такие важные черты, как дисциплинированность и завышенная самооценка [2]. Китайские студенты довольно уклончивы и скрытны, несмотря на внешнюю вежливость, они не любят открываться другим, поэтому студентам сложно наладить с ними контакт. Такой же анализ проводит П. Боур, говоря о том, что «китайские юноши были неуверенными в себе, застенчивыми, замкнутыми и имели мало друзей. Китайские девушки были более ориентированы на общение, но при этом чувствовали себя виноватыми за близкие контакты с представителями не своей расы» $[14$, с.275].

Отличаются и стратегии обучения. В китайских вузах обучение часто ведется на основе коллективных форм взаимодействия, а студентов приучают решать типичные задачи. Линейные однотипные задачи часто формируют отсутствие логического мышления у студентов, отмечает Ц. Тен [12]. Несмотря на то, что умение четко соблюдать правила и выполнять конкретные задачи делает из китайцев хороших, но узких специалистов, при другом типе обучения они начинают испытывать проблемы, им нелегко перестроиться и начать мыслить более широко.

В российской культуре считается нормальным просить помощи и поддержки у других студентов, в то время как китайские студенты привыкли решать проблемы в одиночку. По сравнению с русскими студентами, которые не всегда хорошо умеют работать в коллективе и распределять задачи, китайские студенты хорошо обучены принципам коллективизма, но при этом живут в режиме жесткой соревновательности, отмечает А.А. Маслов [7]. Это тоже вызывает трудности при обучении.

\section{Основная часть}

Большинство исследователей проблем обучения иностранных студентов, направленых, в основном, на студентов языковых специальностей, сходятся во взглядах, что причинами являются языковой и межкультурный барьеры. Отличительной особенностью данного исследования является изучение и анализ причин появления проблем и затруднений китайских студентов, обучающихся на факультете изобразительного искусства Российского государственного педагогического университета им. А.И. Герцена, что позволит в последствии определить педагогические условия; эффективные модели, методы, технологии, средства организации обучения на современном этапе. Методом исследования является анкетирование.

Анкета включает четыре категории вопросов: связанных с общей информацией о респонденте, с карьерным ростом, с процессом обучения, с коммуникацией. В исследовании участвовало 70 респондентов, в выборку вошли студенты всех курсов бакалавриата (1 курс - 8 человек, 2 курс - 9, 3 курс - 7, 4 курс - 9); магистратуры (1 курс -10 человек, 2 курс -12); аспирантуры (9 человек), а также выпускники (6 человек). Соотношение мужчин и женщин составляет соответственно 31/39.

Вопросы, связанные с выяснением перспектив дальнейшего направления деятельности в профессии, с карьерным ростом существенно влияют на текущий учебный процесс; например, если студент в будущем хочет стать дизайнером, а не педагогом, трудности, с которыми сталкиваются на курсах дизайна, станут для него приоритетными. Интересно также узнать сколько студентов связывают свою профессию с деятельностью педагога.

Анализируя ответы на вопрос: «По какой профессии вы хотите работать в будущем?», выявлено, что 44\% студентов хотят быть педагогами в будущем; $14 \%$ - художниками; 22\% - дизайнерами. Бакалавры более склоны к преподаванию в начальной и средней школе, магистры - к преподаванию в средней школе и университете; аспиранты, в основном, хотят стать преподавателями университета.

Системы образования российских и китайских университетов во многом схожи. Но в последние годы системы образования двух стран претерпели серьезные изменения [9], влияющие на обучение студентов, в связи с этим был поставлен вопрос: «Если вы студент-первокурсник, знаете ли вы о системе обучения в университете? (Например, наличие зачётной книжки). Какой способ получения информации об организации обучения вам удобен?» Только 18\% студентов ответили, что хорошо знают систему обучения» и 61\% студентов выразили надежду, что старшие студенты им помогут. Большинство студентов-первокурсников не понимают систему обучения на факультете, так как китайские университеты организуют обучение в соответствии с Положением об управлении студенческим статусом университета и учебным пособием для студентов. Эти документы доступны для всех поступающих студентов, что помогает им получить четкое представление о правилах и положениях университета. Российские вузы редко размещают подобные документы и информацию на официальном сайте, что мешает иностранным студентам правильно понимать правила и регламент работы вуза и системы преподавания.

Таким образом, анализ ответов позволяет сделать следующие выводы для улучшения адаптации студентов КНР: во-первых, следует размещать все правила обучения в открытом для студентов доступе на официальном сайте или на буклете для китайских студентов. Во-вторых, студенческий союз, волонтеры могут организовать соответствующие мероприятия, такие как посещение кампуса с первокурсниками, чтобы ознакомить их с функциями различных отделов. 
В категории вопросов, связанных с процессом обучения, в ответе на вопрос: «Какую форму обучения вы предпочитаете?» более 70\% студентов отдают преимущество смешанному обучению: традиционное и онлайнобучение, так как оно позволяет в любой момент заново обратиться к учебной информации, приостанавливать просмотр обучающих видео, многократно повторять его для полного усвоения.

При ответе на вопрос: «Какой способ освоения учебного содержания для вас предпочтительнее?», 78\% студентов хотели бы, чтобы преподаватели использовали больше наглядного материала, видеофрагментов, слайдов при объяснении учебного материала. Студенты предпочитают визуализацию информации, т.к. контент, отображаемый с помощью изображений и видео, легче для понимания и усвоения студентами художественного факультета.

На вопрос: «Какие задачи обучения сложнее для вас?» - 78\% ответили, что сложнее всего теоретические задания и написание статьи, 12\% - педагогическая практика и участие в деятельности, связанной с обучением детей в российской школе.

На вопросы, связанные с выявлением трудностей при выполнении учебных заданий, студенты ответили, что не понимают требования и цели задания - 54\%), в том числе не понимают требования без примера (22\%); не понимают вопросов преподавателя (4\%); трудно найти и прочитать теоретические материалы (25\%); не знают, где искать информацию (18\%).

Таким образом, ответы в основном сосредоточены на двух аспектах: трудно понять содержание обучения и найти необходимую информацию.

Студенты легче понимают содержание и требования к выполнению заданий при визуализации учебной информации, при демонстрации примеров выполнения заданий. Во время посещения кампуса первокурсниками важно знакомить студентов с местоположением библиотеки и со способами поиска информации в библиотеке.

Следующие вопросы направлены на выяснение проблем при выполнении конкретных заданий. При ответе на вопрос «Есть ли у вас трудности при написании курсовых работ?» 84\% студентов бакалавриата написали, что испытывают большие сложности и только 0,05\% студентов отметили, что понимают требования и не испытывают сложности. 60\% студентов выбрали вариант: «Не знаю, как выбрать тему работы» и 51\% студентов выбрали ответ: «Не понимаю/ не знаю структуру написания работы». 75\% студентов магистратуры заявили, что они не знают, как выбрать тему исследования, с чего начинать самостоятельную работу, какую ставить цель и чем завершить диссертацию. Проблема для студентов факультета изобразительного искусства состоит в том, что им легче понять смысл и содержание художественнопрактической деятельности, чем разобраться в смыслах и правилах написания письменных текстов на тему искусства и педагогики, в том числе научных текстов. Почти 50\% студентов, из числа желающих стать педагогами, отметили сложность в написании теоретических работ, а ведь именно эта категория обучающихся нуждается в отличных теоретических знаниях, так как в своей преподавательской профессии в КНР им придется постоянно писать и публиковать различные теоретические материалы: статьи, методические рекомендации и т.д. для повышения и доказательства своего профессионального уровня [8]. Поэтому проблема поиска эффективных способов работы студентов КНР в области теории является необычайно трудной и важной, поскольку это касается не только учебного процесса, но и их карьеры. Вместе с тем $18 \%$ студентов младших курсов не понимают, зачем нужна теория для будущих педагогов-художников.

Таким образом, определено, что у большинства студентов возникают трудности с выполнением теоретических заданий. Чтобы выяснить, каким образом можно решить проблему, в анкету включен вопрос: «Если задачи теоретического характера сложны для вас, что может помочь вам?». Студенты дали такие ответы: «Дополнительные консультации после занятий» (47\%), «Я надеюсь, что учитель даст больше информации и примеров» (24\%), «Создать группу, которая сможет помочь проанализировать диссертацию» (16\%). Таким образом, возможность получить дополнительную и организованную помощь за пределами учебного времени является одним из важных способов решения ключевой проблемы. Под руководством преподавателя может быть создана группа взаимопомощи в области теоретических дисциплин, существенную поддержку может оказать добровольное участие российских студентов-волонтеров, дистанционная организация консультаций и рефлексии.

Следующие вопросы связаны с осознанием своих проблем в процессе обучении и поиском путей их решения. При ответе на вопрос: «Как вы думаете, какой аспект обучения следует вам у себя улучшить?» 55\% респондентов ответили: «Умение работать в команде», 38\% - «Усидчивость», 31\% - «Приобретение навыков работы с информацией, написание текста». При ответе на вопрос: «Какие курсы, по вашему мнению, полезны для вашего развития или вам интересны?» 57\% выбрали занятия русским языком, 38\% отдали предпочтения художественно-практическим занятиям; 31\% - курсам, связанным с будущей профессией преподавателя; 25\% студентов пожелали овладеть методикой создания научного текста.

Анализ ответов по данной категории вопросов по- 
зволяет сделать вывод, что многие студенты не понимают значения и важности работы в области теории и педагогики искусства, поэтому не уделяют теоретическим дисциплинам достаточного времени и усердия. Очевидно, что в этой сфере обучения требуются дополнительные усилия педагогов и разъяснения важности написания теоретических работ для будущей профессии; определенную роль имеют и рекомендации: по поиску информационных сайтов для студентов при написании теоретических работ; по целенаправленному сбору ее для улучшения навыков письменной речи; по целенаправленной и планомерной работе с научными руководителями.

Отдельную проблему составляют вопросы взаимодействия субъектов образовательного процесса, в том числе педагогического общения. У многих китайских студентов, обучающихся на факультете изобразительного искусства, низкий уровень владения русским языком, так как они испытывают большие сложности при изучении его в короткие сроки. Однако после анкетного опроса отмечено, что многие студенты считают, что общение - это не только языковая проблема. Помимо языковых причин 30\% студентов заявили, что трудности в общении связаны с тем, что у обеих сторон существуют разные способы мышления и поведения; они не могут понять, чего хотят друг от друга. При ответе на вопрос: «Перечислите трудности, которые вы испытываете при общении с педагогами?» 34\% студентов отметили свое плохое знание русского языка; 22\% дали ответ: «Мы думаем по-разному и не понимаем друг друга», 4\% - «Язык и разные мировоззрения не позволяют нам легко договориться».

Различия в языке и культуре делают наше логическое мышление различным [10]. Например, в России студенты используют форму обращения к педагогу по имени и отчеству, а в Китае обращаются: «Учитель» и считают, что говорить имя учителя напрямую невежливо. Преподавателям важно проявлять инициативу в процессе обучения китайских студентов, побуждая их к активному знакомству с русской культурой, объяснить им обычаи и традиции русской культуры, рекомендовать соответствующую литературу.

Общение с другими субъектами образовательного процесса также является частью процесса обучения. При ответе на вопрос «Часто ли вы общаетесь с русскими однокурсниками и преподавателями?» 41\% студентов отметили, что почти никогда не разговаривают с русскими преподавателями и студентами. При ответе на вопрос «Если вы часто общаетесь с русскими однокурсниками и преподавателями, какие темы вы обсуждаете?» $67 \%$ студентов написали: «Задаю им вопросы, которые я не понимаю на занятиях» и 51\% задают вопросы профессионального содержания.
Соответственно, можно говорить о том, что темы, которые студенты обсуждают, полезны для обучения, однако китайские и русские студенты мало общаются между собой. Одной из причин является языковой барьер, но отсутствие уверенности иностранных студентов в себе также является важной причиной. Во-вторых, различаются культурные обычаи, привычки в еде, отношение к религии, понимание фольклора. Различаются понимание вежливости и выражение доброты (например, русские друзья при встрече обнимают друг друга, но в Китае это редко делают). Поэтому, чтобы улучшить общение между студентами двух стран, был задан вопрос: «Какие мероприятия вы хотели посетить или провести, как иностранные студенты, чтобы облегчить общение?». 42\% выбрали варианты «Группа помощи один на один», 31\% - «Экскурсия и выполнение эскизов с натуры». Китайские студенты надеются на помощь от русских студентов, а также надеются организовать деятельности, которая поможет им улучшить общение и профессиональные навыки.

Таким образом, общение российских и иностранных студентов, осведомленность иностранных студентов о русской культуре и этикете смогут улучшить совместные тематические мероприятия.

\section{Выводы}

В результате проведенного исследования установлено, что помимо очевидной проблемы - языкового барьера - существуют следующие проблемы:

- различия в русском и китайском мышлении и в способах обучения приводят к тому, что китайские студенты на начальной стадии не понимают особенности системы обучения и управления образованием в российских вузах, что имеет отрицательное влияние на учебный процесс в целом;

- многие студенты недостаточно мотивированы на изучение теоретических дисциплин, не понимают их значения для овладением будущей профессией педагога, поэтому не уделяют им достаточного времени и усердия;

- затруднено понимание требований и целей учебных заданий; в том числе при написании научного текста;

- особые способы мышления и общения китайских студентов не позволяют при существующей организации учебного процесса качественно и в полной мере овладевать теоретическим знаниями.

Для улучшения адаптации студентов КНР на факультете изобразительного искусства необходимо на первом этапе знакомить и размещать в открытом доступе адаптированную для китайских студентов информацию об организации обучения; провести силами студенческих союзов/волонтеров соответствующие мероприятия, та- 
кие как посещение кампуса с первокурсниками с целью ознакомления их с функциями различных отделов вуза.

Проблема поиска эффективных способов обучения студентов из КНР в области теории остается необычайно важной. При изучении теоретических дисциплин требуются дополнительные усилия и разъяснения педагогов о важности написания теоретических работ для будущей профессии. Необходимо наряду с традиционным он-лайн обучением использовать смешанные модели обучения; на факультете изобразительного искусства уделять внимание качественной визуализации учебной информации, демонстрировать примеры выполнения заданий, знакомить со способами поиска и сбора информации, учить целенаправленной и планомерной работе с научными руководителями диссертаций.

С целью достижения эффективного общения российских преподавателей и студентов с китайскими студентами важно содействовать интеграции иностранных студентов в российское общество, побуждать их к активному знакомству с русской культурой, объяснить обычаи и традиции русской культуры, рекомендовать соответствующую литературу, проводить совместные тематические мероприятия.

\section{ЛИТЕРАТУРА}

1. Береговая 0.А., Кудашов В.И. Интернационализация высшего образования в условиях глобализации // Перспективы науки и образования. - 2019. №3. - C. 31-43.

2. Ван Я. методические принципы и психологические предпосылки обучения китайских студентов русской лексике // Мир науки, культуры, образования. 2019. - №6. - C. 618-620.

3. Голубкина Т.М., Ефимова С.А., Киприянова Н.В., Петросян Д.И., Соколова М.В. Российский вуз глазами иностранных студентов // «Запад-Восток». Научнопрактический ежегодник . - 2018. - №11. - С.223-239.

4. Камара И. Иностранные студенты в российском вузе: социокультурные особенности адаптации и профессиональной социализации: дис. ... канд. пед. наук: 22.00.04. - Краснодар, 2014. - 165 с.

5. Котельникова Е.Ю., Шпортько И.А. Исследование языковых барьеров у студентов технических специальностей при изучении иностранных языков // Филологические науки. Вопросы теории и практики. - 2017. - №2. - С. 13-17.

6. Кухоренко М.Н. Разработка теоретических и методических аспектов обучения личностно-ориентированному общению как эффективное решение проблемы социокультурной адаптации иностранных студентов в российских вузах / М. Н. Кухоренко, К. С. Лелюшкина // Вестник Томского государственного университета. - 2011. - № 349. - С. 162-165.

7. Маслов А.А. Наблюдая за китайцами. Скрытые правила поведения. - М.: РИПОЛ классик, 2010. - 109 с.

8. Соколова Е.Н. Совершенствование методической подготовки будущего художника-педагога в вузе // Известия РГПУ им. А. И. Герцена. - 2011. - №129. C. 32-39.

9. Соломатина М.Н. Сравнительное исследование по управлению китайско российским университетским образованием: дис. ... канд. пед. - Харбин , 2017. - 130 с.

10. Сулейменова э.Д. Тайны вербального мышления, коммуникативная лингвистика и картина мира // Полилингвиальность и транскультурные практики. - 2018. - №4. - С. 546-553.

11. Тянь, Л. Кросс-культурная адаптация китайских учащихся в России: дис. ... канд. - Китай, 2016. - 34 с.

12. Тэн Ц., Ма Ц. Современная сущность «международного образования» в Китае и его реализация в глобальном видении // Сравнительные образовательные исследования. -2019. - №01. - С.36-41.

13. Цзян С., Хун М. Актуальные вопросы, направления и тенденции исследований больших данных в международном образовании-количественный анализ на основе базы данных WOS // Журнал дистанционного обучения. - 2019. - №02. - С. 26-38.

14. Bourne P.G. The Chinese student: acculturation and mental illness // Psychiatry. -1975. -№03, - C. 277-269.

(c) Соколова Елена Николаевна (rgpusokolova@yandex.ru ), Ли Фу (afulili@yandex.com ).

Журнал «Современная наука: актуальные проблемы теории и практики» 